\title{
Differential Diagnoses of Systemic Mastocytosis in Routinely Processed Bone Marrow Biopsy Specimens: A Review
}

\author{
H.-P. Horny ${ }^{\mathrm{a}} \quad$ K. Sotlar ${ }^{\mathrm{b}} \quad$ P. Valent ${ }^{\mathrm{c}}$ \\ anstitute of Pathology, Ansbach, ${ }^{b}$ Institute of Pathology, Ludwig-Maximilians University, Munich, Germany; \\ 'Department of Internal Medicine I (Hematology), University of Vienna, Vienna, Austria
}

\section{Key Words}

Mastocytosis · Mast cell leukemia · Systemic mastocytosis • Bone marrow

\begin{abstract}
Diagnosis of systemic mastocytosis (SM) is mainly based on the morphological demonstration of compact mast cell infiltrates in various tissue sites. In almost all patients such infiltrates are detected in the bone marrow. Reliable immunohistochemical markers for the diagnosis and grading of SM have been established, but various differential diagnoses including myeloproliferative neoplasms, basophilic and eosinophilic leukemias may be very difficult to delineate. Even more challenging is the recognition of hematological neoplasms with signs of mast cell differentiation but not fulfilling diagnostic criteria for SM, especially the rare myelomastocytic leukemia. It is also important to separate the reactive state of mast cell hyperplasia from indolent variants of SM, especially those with a very low degree of bone marrow infiltration and absence of compact mast cell infiltrates. When the lymphocytic component of the SM infiltrate is very prominent, SM may be confused with an indolent lymphoma, especially lymphoplasmacytic lymphoma which almost always shows a marked reactive increase in mast cells. In aggressive and leukemic variants of SM, mast cells may be very atypical and devoid of metachromatic granules. This hypogranulation can be regarded as cellular atypia and may lead
\end{abstract}

\section{KARGER}

Fax +4161306 1234 E-Mail karger@karger.ch www.karger.com

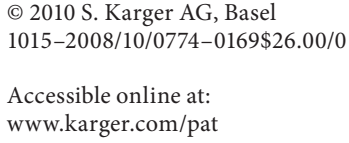

to the misdiagnosis aspect of monocytic leukemia or histiocytic neoplasm. Regarding immunohistochemical anomalies, mast cells in aggressive and leukemic SM have been found to express CD30 (Ki1-antigen). Thus, anaplastic large cell lymphoma or Hodgkin's disease may first be considered rather than SM. There is increasing evidence that most patients with long-standing adult-type urticaria pigmentosalike skin lesions have in fact indolent SM. Therefore, such skin lesions are an important clue to the correct diagnosis in these patients. However, in aggressive or leukemic SM skin lesions are usually absent and then the correct diagnosis relies on an appropriate investigation of bone marrow biopsy specimens using both SM-related immunohistochemical markers (tryptase, KIT, CD25, CD30) but also markers excluding potential differential diagnoses. Investigation for presence of the activating KIT point mutation D816V is very helpful to establish a correct diagnosis of SM in all the difficult cases exhibiting a low degree of bone marrow infiltration or puzzling morphological findings.

Copyright $\odot 2010$ S. Karger AG, Basel

\section{Introduction}

Mastocytosis is a hemopoietic disorder of bone marrow origin comprising an extremely heterogeneous array of subentities with greatly varying clinical and pathomorphological features [1]. The complexity of this unusual

Prof. Dr. med. Hans-Peter Horny

Institute of Pathology Ansbach

Escherichstr. 6

DE-91522 Ansbach

Tel. +49 981488 830, Fax +49981 488 8310, E-Mail horny@ patho-ansbach.de 
disorder can best be shown by the fact that a hemopoietic stem cell-derived disorder in most patients primarily presents as a dermatological disease. The common denominator of mastocytosis is the demonstration of multifocal compact tissue mast cell infiltrates [2]. The presence of such compact mast cell infiltrates outside the skin is the key finding for systemic mastocytosis (SM). Compact mast cell infiltrates are considered as a major diagnostic criterion and represents a crucial indicator for the pathologist to be able to correctly assess or exclude mastocy tosis morphologically. The multifaceted features of mastocytosis explain the broad range of differential diagnoses, including reactive and neoplastic states. Moreover, the list of differential diagnoses varies according to the diagnostic approach to the disease. While patients with longstanding adult-type urticaria pigmentosa (the most common form of cutaneous mastocytosis) are staged for the presence of indolent systemic mastocytosis (ISM) by investigation of bone marrow trephine biopsy specimens, isolated bone marrow mastocytosis as a special subvariant of ISM without skin involvement is an incidental finding in a small subgroup of patients with suspected hematological disorders, unexplained osteoporosis, or severe anaphylaxis after bee or wasp stings.

In the following, morphological and molecular key features for the diagnosis of mastocytosis are presented together with clues for proper subclassification but also for delineation of mast cell hyperplasia, hematological disorders with signs of mast cell differentiation not fulfilling diagnostic criteria of mastocytosis and the large panel of possible differential diagnoses within the spectrum of hematological neoplasms.

\section{Material and Methods}

The present study is based on archival material gathered in a Center of Reference for Hematopathology of Mastocytosis within the European Competence Network of Mastocytosis (ECNM) located at the Institute of Pathology in Ansbach, Germany. The registry consists of nearly 700 cases of well-documented mastocytosis including immunohistochemical and molecular pathological findings. All subtypes of mastocytosis were recorded. All cases were analyzed immunohistologically with antibodies against the mast cell-related antigens tryptase and CD117 (KIT) but also against CD25 and CD30 to assess an aberrant phenotype of mast cells that is only present in neoplastic states of mastocytosis. Association of SM with a hematological non-mast cell clonal disorder (SM-AHNMD) makes it necessary to apply a larger panel of antibodies to be able to subclassify the 'AHNMD' according to WHO criteria. When available, smears of blood and bone marrow were also investigated with special attention to the number and cytomorphological aspects of mast cells.

\section{Diagnostic Criteria for Mastocytosis [3]}

(1) Main criterion.

Multifocal compact tissue infiltrate of mast cells.

(2) Minor criteria.

(2.1) Prominent spindling of mast cells ( $>25 \%)$.

(2.2) Aberrant immunophenotype of mast cells with expression of CD25 (and/or CD2).

(2.3) Activation point mutations at codon 816 of KIT (usually D816V).

(2.4) Chronically elevated serum tryptase ( $>20 \mathrm{ng} / \mathrm{ml}$ ).

Diagnosis of mastocytosis can be established if the major and at least 1 minor criterion or at least 3 minor criteria are fulfilled.

Note that the diagnosis of mastocytosis is only possible when appropriate investigations are performed by the pathologist. Morphological criteria (1, 2.1 and 2.2) alone are sufficient to enable a diagnosis of mastocytosis to be confirmed by the pathologist. In cases where the major criterion is missing, however, at least one additional molecular and/or serological finding has to be considered. Altogether, in about $20 \%$ of cases compact mast cell infiltrates cannot be detected and diagnosis of mastocytosis is based on 3 or 4 minor criteria.

\section{Immunohistochemical Key Features}

Immunohistochemical diagnosis of SM in the bone marrow (but also in other tissue sites) requires three antibodies directed against the following antigens: tryptase, CD117 (KIT) and CD25 [4]. In most patients with SM-AHNMD, diagnosis of the 'AHNMD' can be achieved only by application of a broader panel of antibodies pending on the suspected subtype of the associated neoplasm. Cases missing any compact mast cell infiltrates cannot be diagnosed without immunohistochemistry. It is essential to be aware that mast cells in reactive and neoplastic states and all stages of maturation coexpress tryptase and CD117. Cells expressing only tryptase or CD117, respectively, are not mast cells. Round tryptase-positive CD117negative cells can be basophilic granulocytes or myeloblasts. An increase in such cells is seen in neoplastic states like basophilic leukemia, chronic myeloid leukemia or myelomastocytic leukemia. Rarely, compact infiltrates consisting exclusively of round tryptase-expressing cells are detected, a finding which has been termed TROCIbm and which is seen only in neoplastic states [5]. TROCI-bm deserves further immunohistochemical clarification using antibodies against CD117, CD25, and CD34. 
Focal TROCI-bm occurs in common-type SM, in welldifferentiated SM (note: mast cells are CD25-negative here), in basophilic and chronic myeloid leukemias while diffuse TROCI-bm is encountered in aggressive SM, mast cell leukemia, tryptase-positive acute myeloid leukemia and myelomastocytic leukemia. CD117-positive tryptasenegative cells can be progenitor/blast cells or immature erythroblasts but are also seen in the setting of some solid neoplasm that hardly infiltrate the bone marrow (gastrointestinal stroma tumor/GIST, seminoma, malignant melanoma, etc.). However, virtually all spindle-shaped tryptase-expressing cells are in fact mast cells. Expression of CD25 by mast cells defines a phenotypic aberrancy that is almost exclusively seen in mastocytosis [6]. One of the rare exceptions to the rule is myeloproliferative neoplasms with eosinophilia (MPNEo) which may contain large numbers of spindle-shaped CD25-positive mast cells usually without fulfilling diagnostic criteria for SM [7]. Recent findings yielded a usually strong expression of CD30 on neoplastic mast cells in the setting of aggressive or leukemic SM, whereas CD30 expression was low or even missing in most cases of indolent SM [own unpubl. obs.].

In the following, morphological key diagnoses are defined and the differential diagnostic aspects of the disease are highlighted (table 1).

\section{Mast Cell Hyperplasia}

By definition, mast cell hyperplasia represents a reactive increase in mast cells with very characteristic morphological features. Mast cells are loosely scattered throughout the tissues without tendency to form compact infiltrates (fig. 1). Usually, mast cells are round and contain abundant metachromatic granules. However, collagen fibrotic tissue may also contain increased numbers of mast cells which here show a spindle-shaped appearance and resemble fibrocytes/fibroblasts in conventional HE staining. Such fibrotic foci may easily be misinterpreted as mastocytosis. Since mast cells here do not aggregate in dense clusters and do not express CD25, this is not mastocytosis but rather could be preliminarily, termed 'fibromastocytic lesion'. Compact groups of mast cells have very rarely been seen in patients treated with hematopoietic growth factors like SCF. Three subvariants of mastocy tosis have to be separated from mast cell hyperplasia:

(1) Indolent SM, especially regarding the usually low degree of bone marrow infiltration.

(2) Isolated SM of the bone marrow which also shows a low degree of infiltration.
Table 1. SM: main differential diagnoses

\begin{tabular}{|c|c|}
\hline Diagnosis & Differential diagnosis \\
\hline Mast cell hyperplasia & $\begin{array}{l}\text { Indolent SM } \\
\text { Occult mastocytosis } \\
\text { Well-differentiated SM }\end{array}$ \\
\hline Indolent SM & $\begin{array}{l}\text { Mast cell hyperplasia } \\
\text { Occult mastocytosis } \\
\text { Cutaneous mastocytosis } \\
\text { Isolated mastocytosis of BM } \\
\text { Smoldering SM } \\
\text { Non-Hodgkin's lymphoma } \\
\text { Hairy cell leukemia } \\
\text { Histiocytic neoplasm } \\
\text { Granulomatous disease }\end{array}$ \\
\hline Smoldering SM & $\begin{array}{l}\text { Myeloproliferative neoplasm } \\
\text { Eosinophilic leukemia } \\
\text { Malignant lymphoma } \\
\text { CMML } \\
\text { SM-AHNMD }\end{array}$ \\
\hline Aggressive SM & $\begin{array}{l}\text { Smoldering SM } \\
\text { Aleukemic MCL } \\
\text { SM-AHNMD } \\
\text { CD30+ malignant lymphoma }\end{array}$ \\
\hline MCL & $\begin{array}{l}\text { Aggressive SM } \\
\text { Aleukemic MCL } \\
\text { Basophilic leukemias } \\
\text { Myelomastocytic leukemia } \\
\text { SM-AHNMD } \\
\text { Tryptase+ AML } \\
\text { CD30+ malignant lymphoma }\end{array}$ \\
\hline SM-AHNMD & $\begin{array}{l}\text { Aggressive SM } \\
\text { Myelomastocytic leukemia }\end{array}$ \\
\hline 'CD30+ mastocytosis' & $\begin{array}{l}\text { Hodgkin's lymphoma } \\
\text { Anaplastic LCL } \\
\text { Seminoma }\end{array}$ \\
\hline 'CD68+ mastocytosis'* & $\begin{array}{l}\text { Histiocytosis } \\
\text { Monocytic leukemia }\end{array}$ \\
\hline 'CD25+ mastocytosis'* & Hairy cell leukemia \\
\hline
\end{tabular}

$\mathrm{SM}=$ Systemic mastocytosis $; \mathrm{BM}=$ bone marrow $; \mathrm{MCL}=$ mast cell leukemia; AHNMD = associated hematologic non-mast cell disorder; LCL = large cell lymphoma; CMML = chronic myelomonocytic leukemia.

* In most patients with SM, MC are CD68+ and CD25+. 


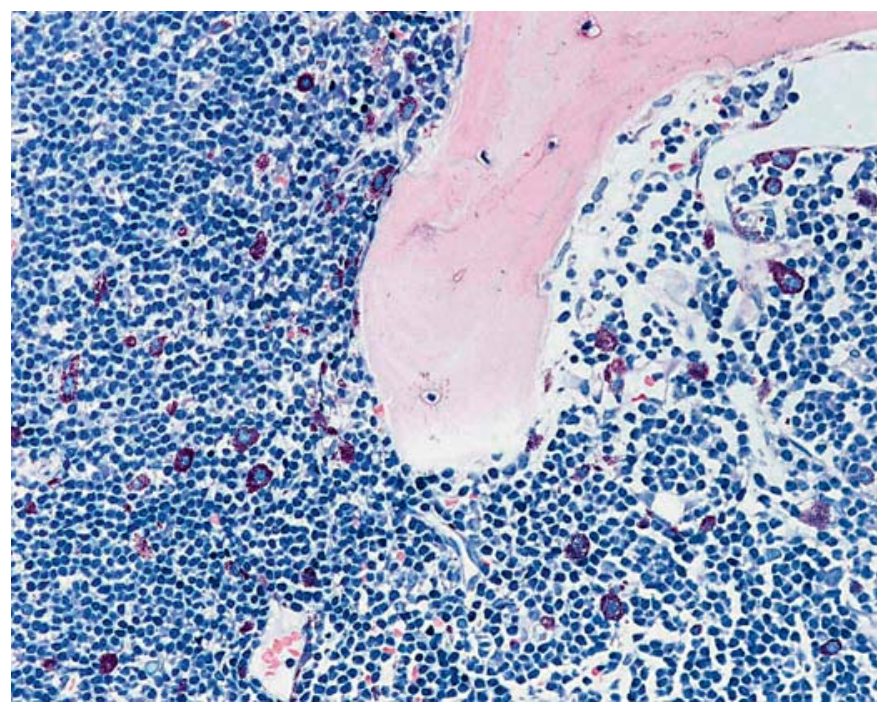

Fig. 1. Mast cell hyperplasia. Extremely hypercellular bone marrow with packed infiltration by a lymphocytic lymphoma. Note the increase in loosely scattered round strongly metachromatic mast cells without tendency to group or to form compact infiltrates. Mast cell hyperplasia is a very common finding in this type of malignant lymphoma. Giemsa.

(3) Well-differentiated SM [8], considering the cytomorphology of cells that are exclusively round and that do not express CD25 (fig. 2).

In contrast to mast cell hyperplasia where round mast cells dominate the picture, indolent SM and isolated bone marrow SM usually show increased numbers of spindleshaped mast cells exhibiting an atypical immunophenotype expressing CD25 (fig. 3, 4). In most cases at least a few small compact mast cell infiltrates can be detected when appropropriate immunostainings like tryptase and anti-CD117 are applied [9]. The demonstration of the activating point mutation KITD816V in the overwhelming majority of cases clearly underlines such histological findings to be interpreted as clonal expansion of intramedullary mast cells in the setting of mastocytosis [10].

\section{Indolent Systemic Mastocytosis}

Indolent systemic mastocytosis (ISM) usually shows a multifocal but low degree of bone marrow infiltration (less than $5 \%$ of section area) and is the most common diagnosis for adult patients with long-standing urticaria pigmentosa (cutaneous mastocytosis). ISM has to be separated from mast cell hyperplasia, indolent lymphoma and some subtypes of SM that usually also show a minor degree of bone marrow infiltration.

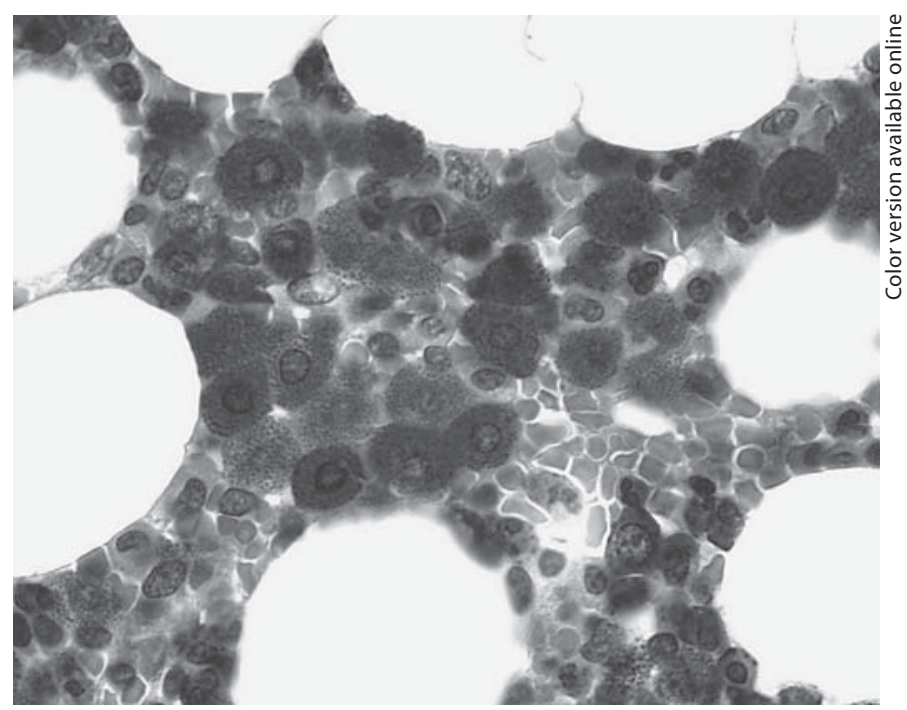

Fig. 2. Well-differentiated systemic mastocytosis. Small compact infitrate exclusively consisting of round mast cells that strongly react with chloroacetate esterase. Naphthol AS-D chloroacetate esterase.

(1) Isolated bone marrow mastocytosis is incidentally detected in a subgroup of patients with anaphylactic reactions after hymenoptera stings. Since these patients usually have no skin lesions of urticaria pigmentosa, it is crucial for the pathologists to assess or exclude SM by applying immunohistochemistry in all cases. If spindle-shaped loosely scattered CD25positive mast cells are detected, even in low numbers, a molecular pathological analysis has to performed. Many of these patients then are found to have SM based on three minor diagnostic criteria (e.g. aberrant immunophenotype, KITD816V and elevated serum tryptase) since compact mast cell infiltrates are often missing.

(2) Cutaneous mastocytosis should be diagnosed in the adult only after histological investigation of an adequate bone marrow trephine biopsy specimen. Our own unpublished observations show that most but not all patients with long-standing urticaria pigmentosalike skin lesions do in fact have ISM. In contrast, almost all children with cutaneous mastocytosis do not have systemic disease, although it should be stated that their bone marrow is usually not evaluated histologically. The notion of a pure juvenile-type of cutaneous mastocytosis is underlined by the fact that most 


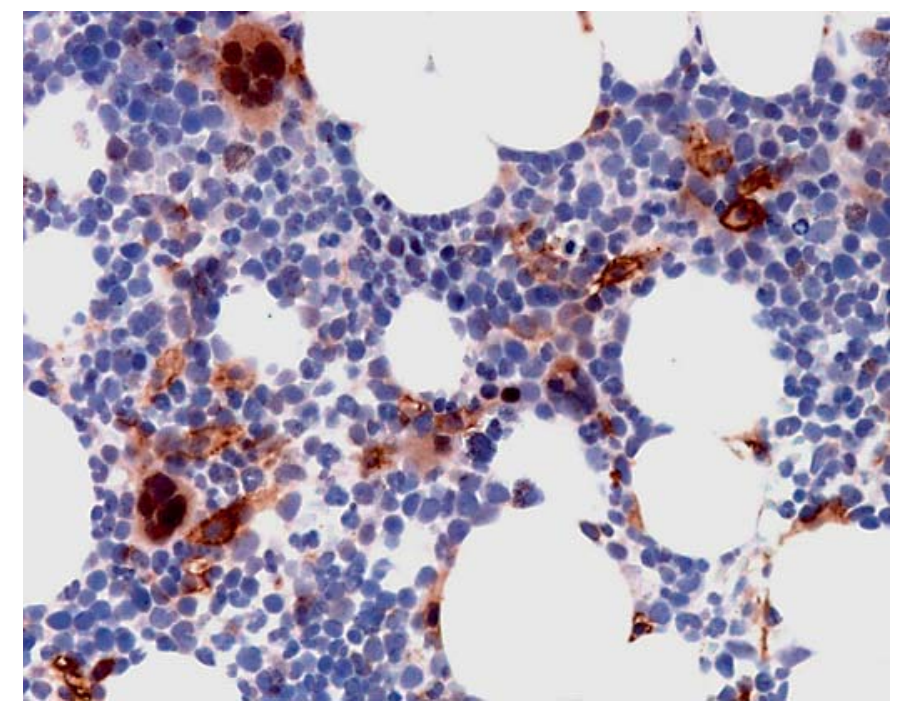

Fig. 3. Indolent systemic mastocytosis. Loosely scattered spindleshaped mast cells with aberrant immunophenotype and expression of CD25 can easily be detected. This is a very typical finding in indolent systemic mastocytosis, but without presence of compact infiltrates (not depicted) the presented morphological aspects alone do not fulfill criteria for diagnosis of systemic mastocytosis. Anti-CD25 (ABC method).

patients show spontaneous regression of skin efflorescences at puberty [11].

(3) Well-differentiated SM is easily excluded by the absence of aberrant CD25 expression. It is important to be aware that rare cases of 'common' type ISM with exclusive round cell appearance do exist (fig. 5).

(4) Smoldering and aggressive SM may be difficult to exclude in some exceptional cases of ISM with extensive infiltration of the bone marrow (up to $70 \%$ of section area). The presence of B-findings (organomegaly) indicates smoldering SM which often shows KITD816V mutation in non-mast cell-lineage cells and cytological atypia of blood cell precursors. The full picture of a myelodysplastic syndrome (MDS), however, is not present and SM-AHNMD should not be diagnosed. The presence of $\mathrm{C}$-findings (indicating organ insufficiency due to mast cell infiltration) is the key finding for the diagnosis of aggressive SM.

(5) Cases of ISM may show disseminated follicle-like lymphocytic aggregates adjacent to or intermingled with the neoplastic mast cells leading to the primary aspect of a low-grade malignant non-Hodgkin's lymphoma at first glance. Lymphocytic lymphomas (chronic lymphocytic leukemia/CLL and lymphoplasmacytic lymphoma) here are easily misdiagnosed due to their high

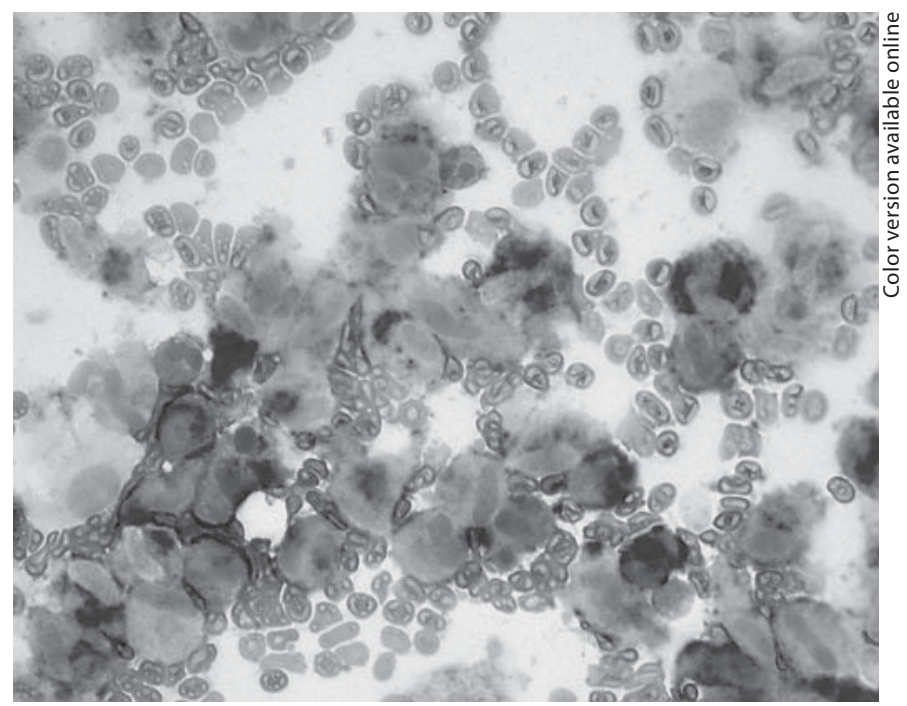

Fig. 4. Mast cell leukemia. Cytomorphology of a bone marrow smear showing a striking increase in mast cells with expression of CD25. Quantitative aspects fulfill criteria for diagnosis of mast cell leukemia. Anti-CD25 (ABC method).

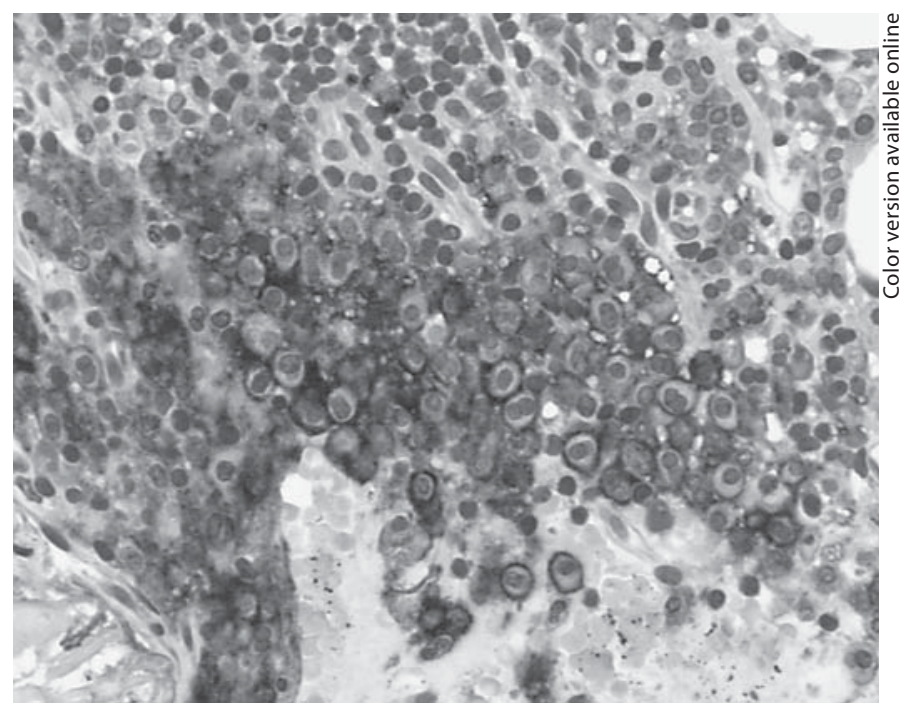

Fig. 5. Indolent systemic mastocytosis. Large compact infiltrate exclusively consisting of round mast cells is shown. Since mast cells clearly express CD25, this is not a case of well-differentiated systemic mastocytosis. Anti-CD25 (ABC method). 


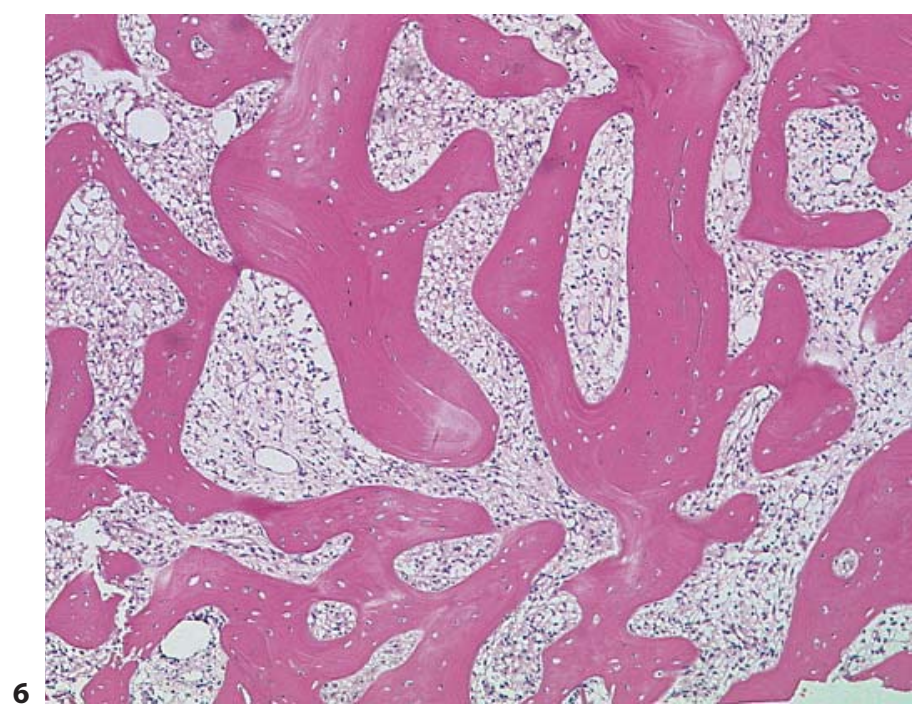

Fig. 6, 7. Malignant histiocytosis. Diffuse infiltration of the bone marrow by histiocytic medium-sized cells with aplasia of normal blood cell precursors and fat cells. Note the marked osteosclerosis. Immunophenotypical analysis revealed expression of histiocyte-

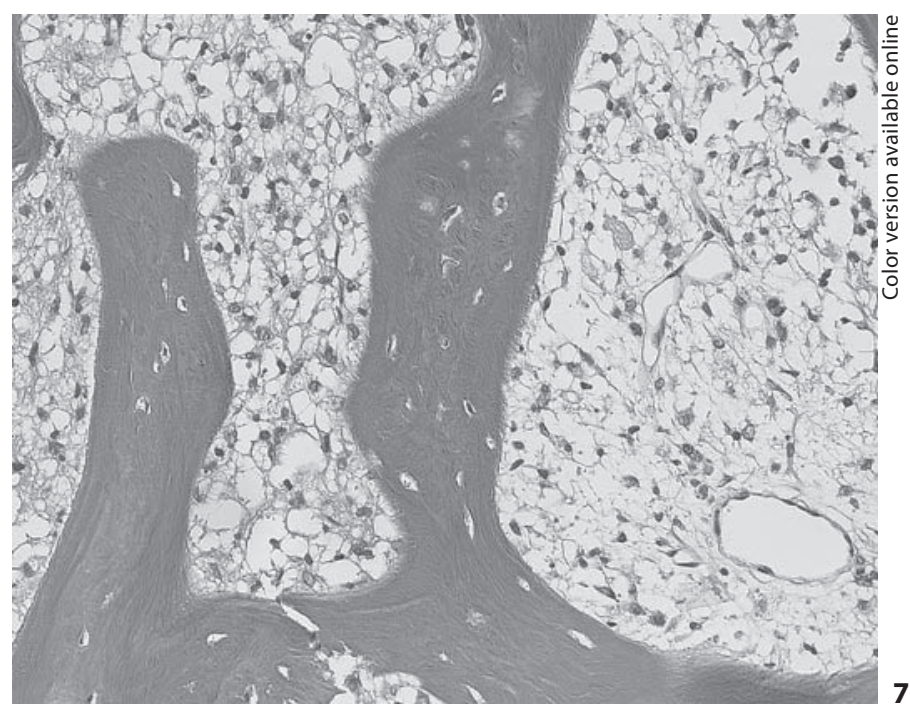

related antigens like CD68 and CD163 by neoplastic cells (not depicted). Since all myeloid antigens including tryptase were completely negative, this case was regarded as an extremely rare 'true' malignant histiocytosis. HE. content of mast cells. However, lymphocytes in ISM usually show no immunophenotypical anomalies. An extremely uncommon finding is an association of SM with CLL perfectly imitating the histological picture of indolent SM with mixed (mast cell/lymphocyte) infiltrates. Diagnosis of CLL here could be only confirmed by the presence of an atypical immunophenotype of lymphocytes coexpressing CD5, CD20 and CD23 [12].

\section{Aggressive Systemic Mastocytosis}

Aggressive systemic mastocytosis (ASM) is morphologically characterized by a marked degree of bone marrow infiltration $(>30 \%)$ which may be either multifocal or diffuse-compact [13]. ASM has to be separated from other high-grade variants of SM and a few rare myeloid neoplasms.

(1) The major differential diagnosis of ASM is SMAHNMD since the 'AHNMD' may be almost obscured by the massive mast cell infiltrate but is often easily detectable when blood and bone marrow smears are investigated.

(2) Mast cell leukemia may show very similar histological pictures as can be seen in ASM as well as a comparable degree of bone marrow infiltration. In typical cases of mast cell leukemia, the degree of reticulin fibrosis is markedly lower than in ASM. Moreover, there is a more diffuse ('leukemia-like') infiltration pattern in mast cell leukemia contrasting to the more multifocal involvement seen in ASM. It is of outstanding importance to analyze blood and bone marrow smears. In mast cell leukemia more than $20 \%$ of nucleated bone marrow cells have to be identified as mast cells (counting of mast cells should not be performed in or around the crushed particles). Moreover, ASM may progress into most cell leukemia (secondary MCL).

(3) Separation of ASM from smoldering SM and ISM is not always possible on the basis of bone marrow histology alone.

(4) It may be very difficult or even impossible to separate hematological neoplasms like monocytic leukemia, basophilic and eosinophilic leukemia, malignant histiocytosis (fig. 6, 7), hairy cell leukemia, myelomastocytic leukemia and tryptase-positive acute myeloid leukemia from ASM unless immunohistochemical staining is applied.

(5) A major proportion of cases with high-grade SM (ASM, SM-AHNMD and mast cell leukemia) show strong expression of CD30 by a majority of neoplastic mast cells (fig. 8-12). Unless antitryptase staining is performed, diagnoses of malignant lymphoma (Hodgkin's sarcoma, anaplastic large cell lymphoma) or even malignant germ cell tumor may be considered. 

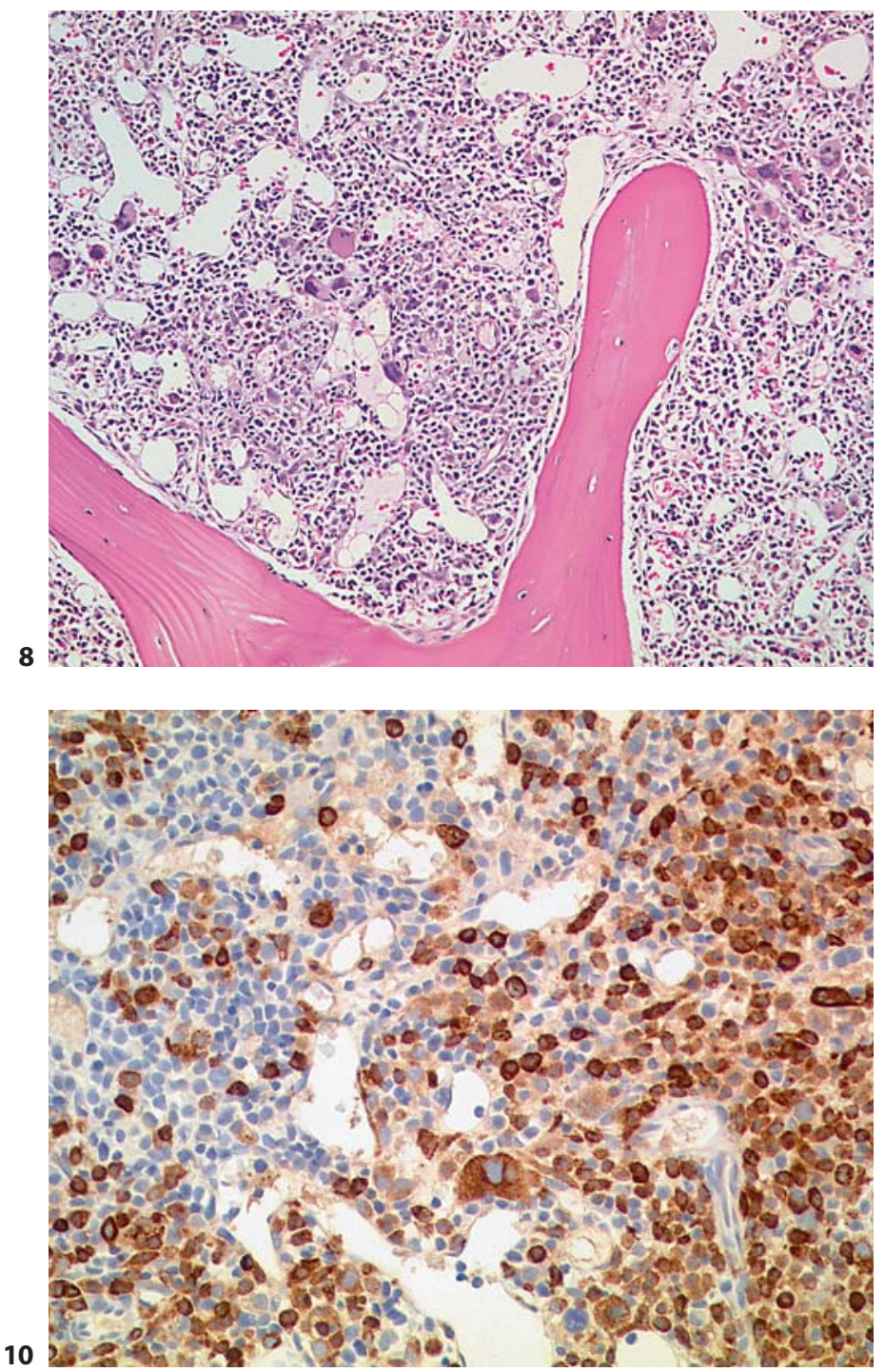

Fig. 8-12. Mast cell leukemia. Mast cell leukemia with diffuse infiltration of the bone marrow is shown. Note the dilated sinus-like prominent vessels. Mast cells coexpress tryptase and CD117 (not depicted) but also CD30. Since some multinucleated CD30-positive giant cells are present, diagnosis of a malignant lyphoma was initially considered. Cellular bone marrow smears reveal an abundance of round hypogranulated, often vacuolated mast cells. HE (fig. 8, 9). Antitryptase/AA1 (ABC mehod) (fig. 10). AntiCD30 (fig. 11). Wright-Giemsa (fig. 12).
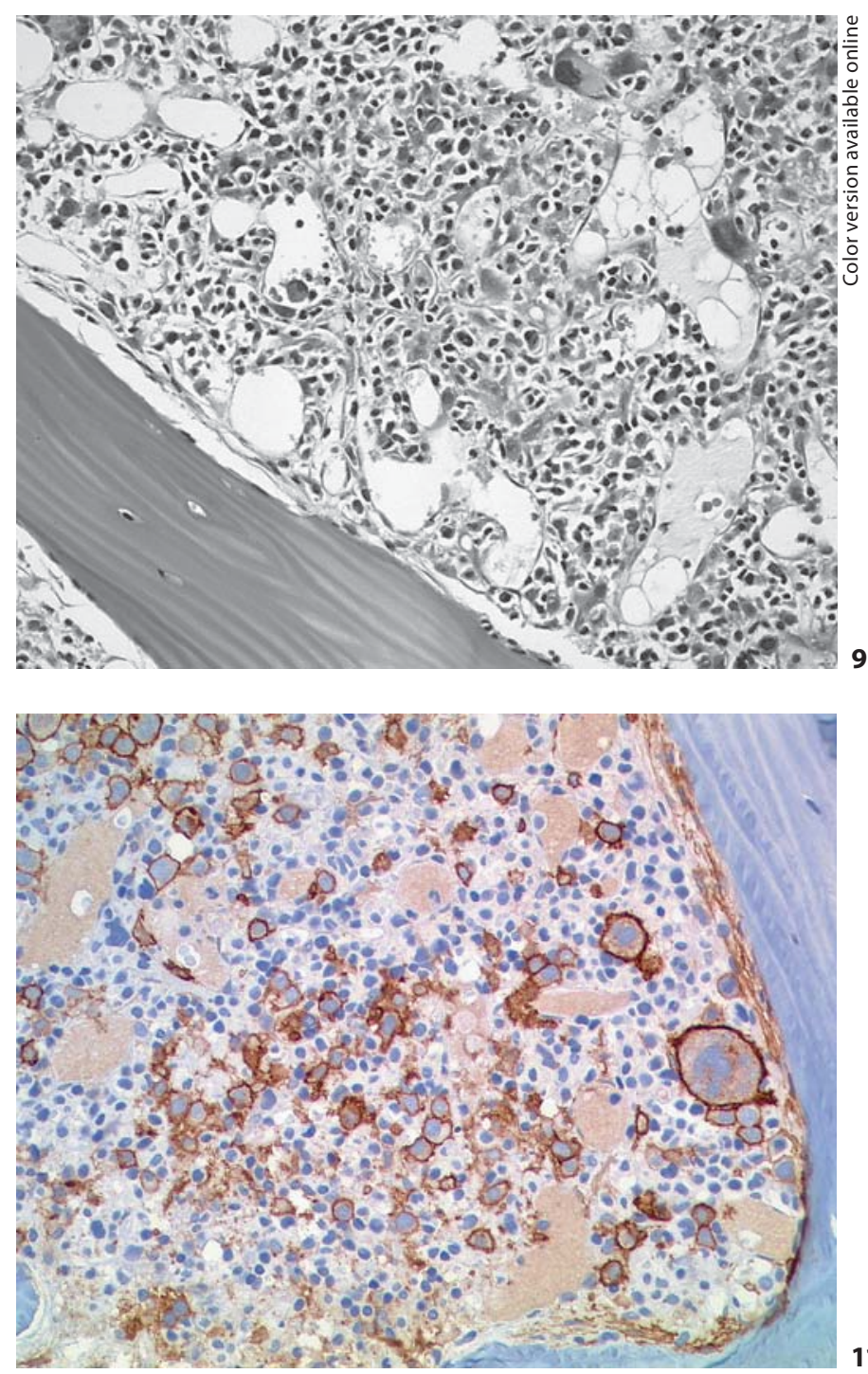

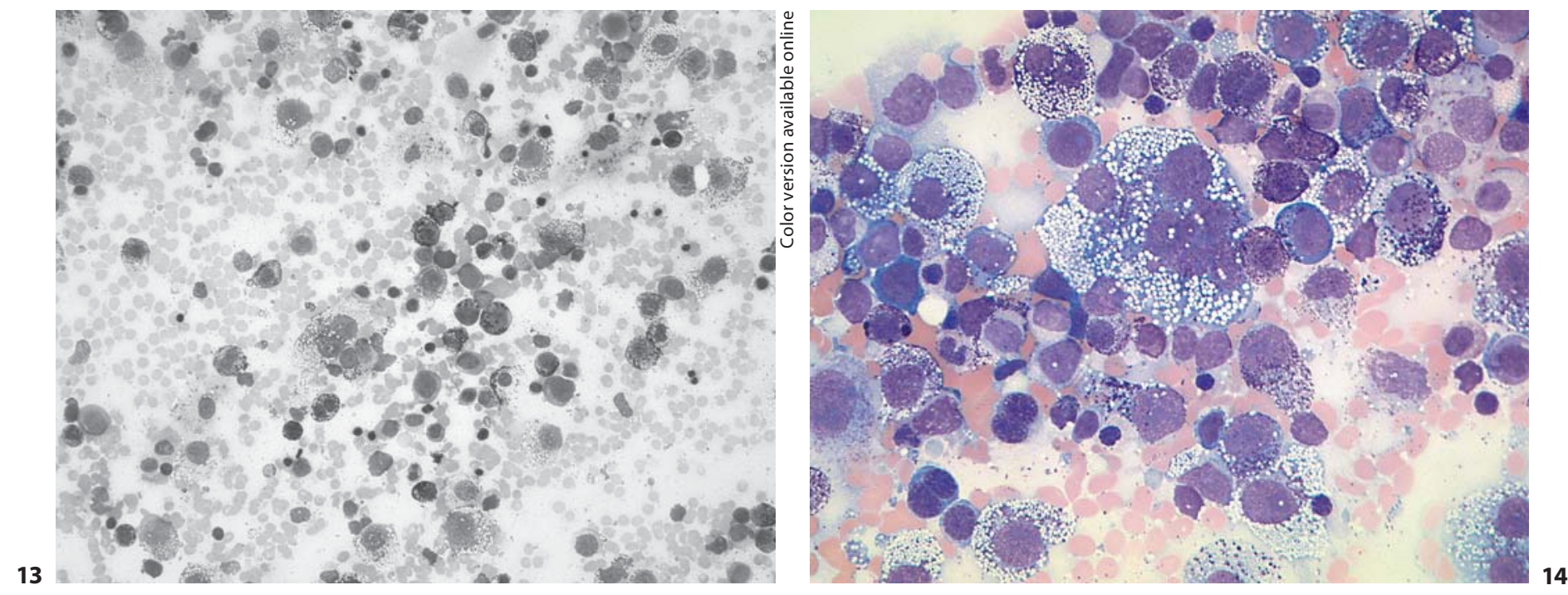

Fig. 13-15. Mast cell leukemia. Cytomorphological aspects of mast cell leukemia in bone marrow smears. Figures 13 and 14 show the more common round cell type, while figure 15 reveals the rare spindle-shaped variant of mast cell leukemia. Mast cells in both subvariants are hypogranulated. Normal blood cell precursors are almost absent. Wright-Giemsa.

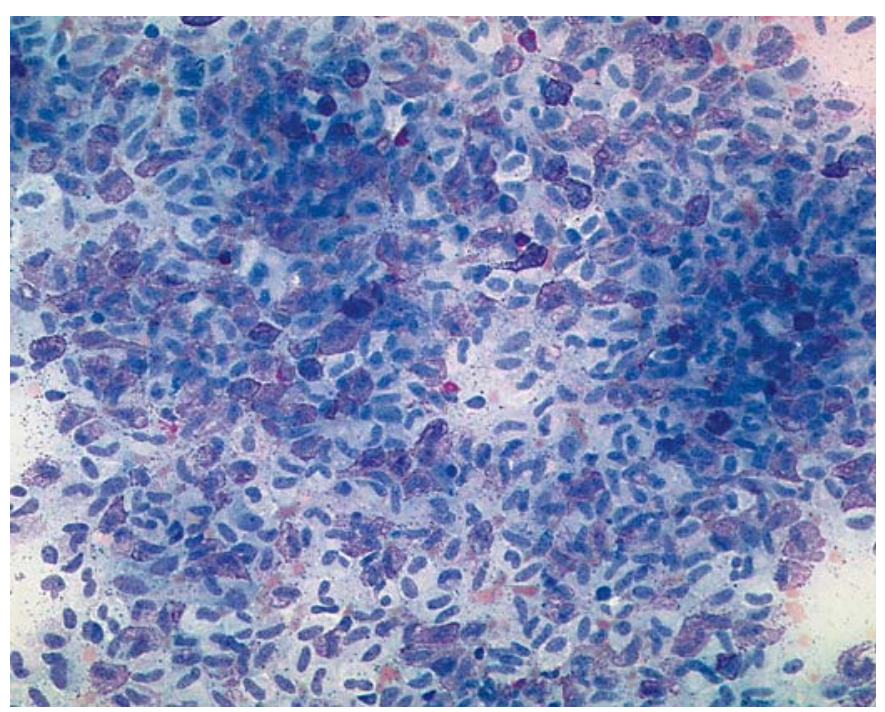

\section{Mast Cell Leukemia}

Mast cell leukemia (MCL) is a very rare hematological disease within the spectrum of mastocytosis due to its unique cytomorphological, immunophenotypical and molecular pathological features [14]. It is likely that MCL belongs to the rarest forms of human leukemias. Morphologically, typical cases of MCL show a diffuse-compact bone marrow infiltration with marked reduction of fat cells and blood cell precursors. As previously stated, MCL is defined by an increase in mast cells in bone marrow smears exceeding $20 \%$ of all nucleated cells. Presence of circulating mast cells in the blood (at least $10 \%$ of leukocytes) separates MCL from its (more common) aleukemic subvariant. Cytomorphologically, two major subtypes of MCL are distinguishable: the common round- cell and the rare spindle-cell variant (fig. 13-15). MCL must be separated from other high-grade variants of SM and some non-mast cell hematological neoplasms.

(1) Aggressive (but also smoldering and, rarely, indolent) SM are histologically indistinguishable from MCL because the bone marrow can be diffusely infiltrated in all these subvariants of SM.

(2)SM-AHNMD is very difficult to assess or exclude because the leukemic infiltration may almost obscure the 'AHNMD' which can only be recognized by meticulous analysis of blood and bone marrow smears [15]. Cases of MCL associated with myelodysplastic syndromes and chronic myelomonocytic leukemia do exist thus enabling diagnoses like MCL-MDS or MCLCMML to be established. 

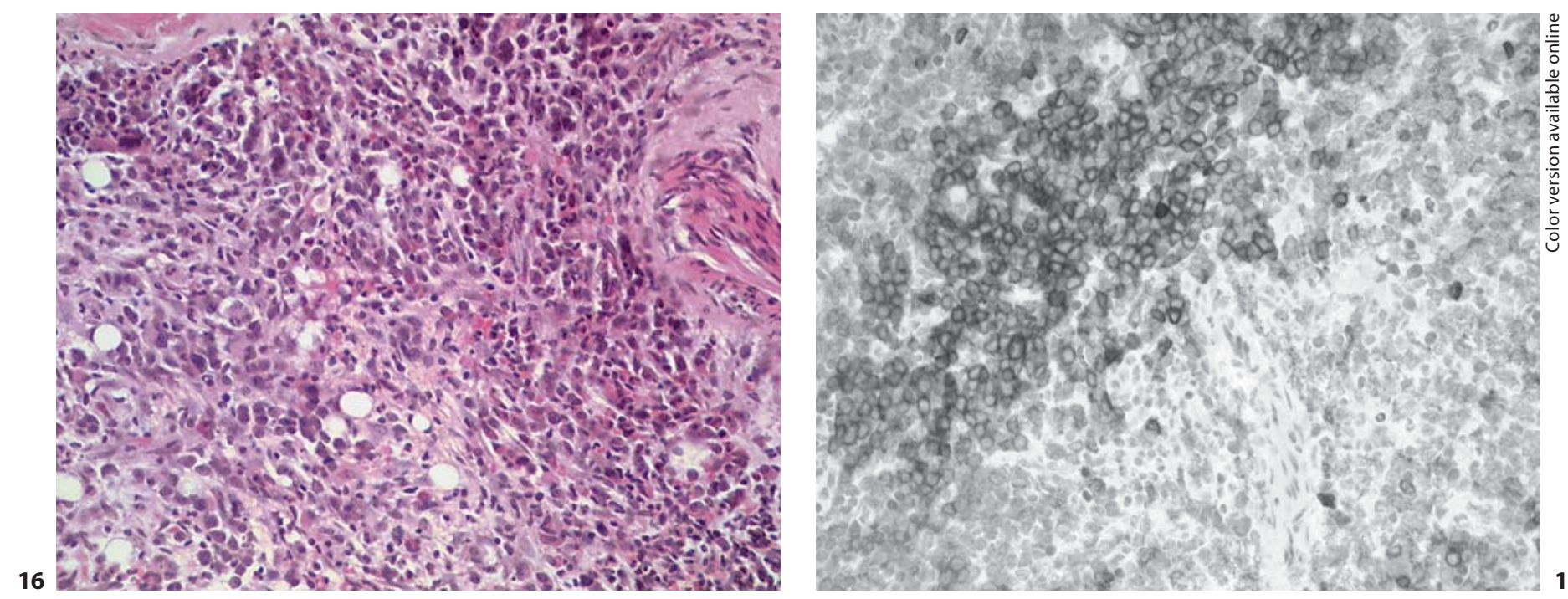

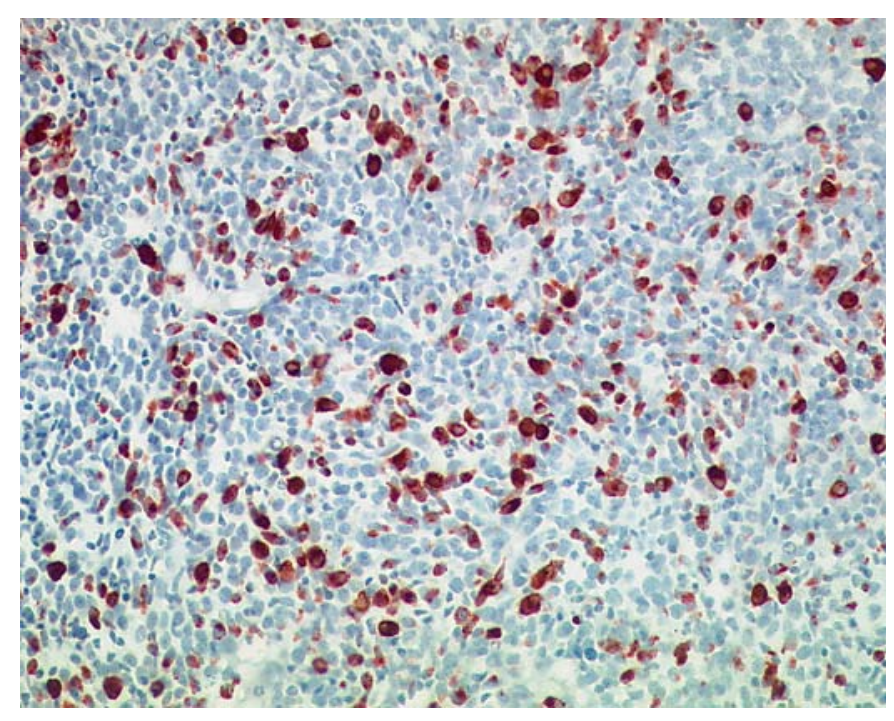

Fig. 16-20. Chronic basophilic leukemia. Bone marrow histology has features of an uncommon myeloproliferative or myelodysplastic neoplasm. Immunohistochemical investigations reveal clusters of CD117-positive but tryptase-negative medium-sized blast cells. There is also an increase in small round tryptase-positive CD117-negative cells which can be identified as basophils by using an antibody against the basophil-specific antigen 2D7 (not commercially available). Blood smear shows an increase in circulating basophils constituting more than $50 \%$ of all leukocytes. Cytogenetics did not reveal the bcr-abl fusion gene. HE (fig. 16). Anti-CD117 (ABC method) (fig. 17). Antitryptase/AA1 (fig. 18). Anti-2D7 (fig. 19). Wright-Giemsa.

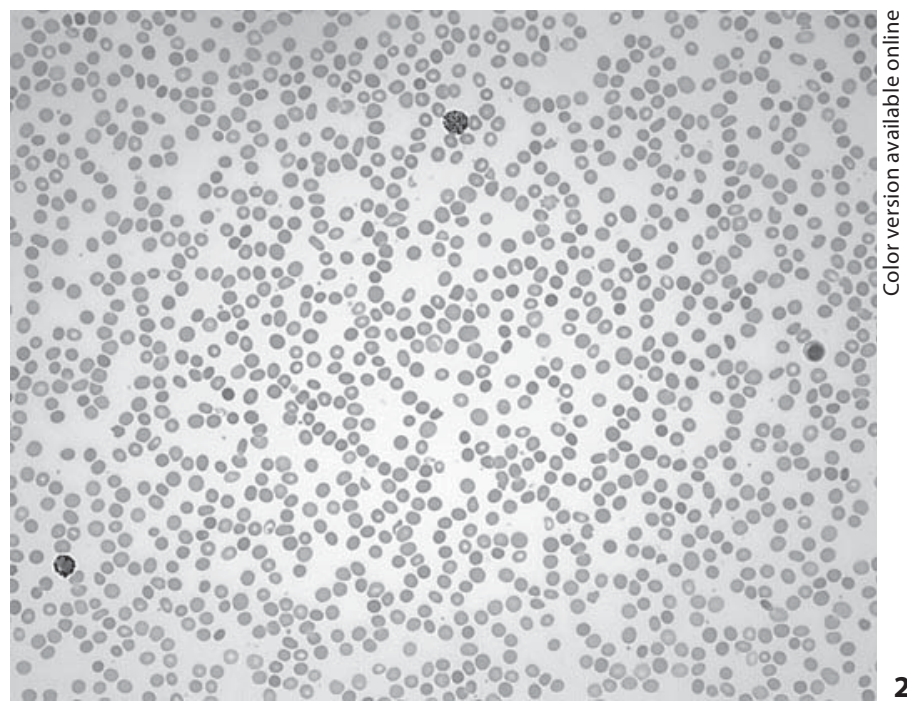


(3) The common round-cell variant of MCL must be separated from myelomastocytic and basophilic leukemia. By definition, the extremely rare myelomastocytic leukemia shows features of mast cell differentiation but does not fulfill criteria of SM, especially the activating point mutation KITD816V is missing as well as compact mast cell infiltrates [16].

Tryptase-positive acute myeloid leukemia (T+AML) should be separated from myelomastocytic leukemia. $\mathrm{T}+\mathrm{AML}$ is characterized by a significant increase in tryptase-expressing blast cells in an otherwise unremarkable AML which usually exhibits immunophenotypical characteristics of subtype FABM1. Basophilic leukemia may be difficult to separate from MCL because there is an abundance of round tryptase-expressing neoplastic cells in both neoplasms. While mast cells of MCL must show expression of CD117 (KIT), this antigen is missing on neoplastic basophils of basophilic leukemia (fig. 16-20). The spindle-shaped variant of MCL is very rare. Differential diagnosis includes a variety of here extremely uncommon tumors like gastrointestinal stromal tumor (GIST), malignant melanoma, spindle-shaped plasma cell myeloma [17] and mesenchymal tumors with prominent fibroblastic differentiation.

\section{Myelomastocytic Leukemia}

The most important differential diagnosis of MCL is myelomastocytic leukemia (MML). In MML, the chance to be cured by stem cell transplantation may be better compared to MCL and ASM. MML is an advanced myeloid neoplasm with an increase in blast cells (usually RAEB or overt AML) but also a marked increase in immature MC and/or metachromatic blast cells (more than $10 \%$ of nucleated cells in bone marrow smears). Mast cells in MML usually express CD117 and tryptase but lack CD2 and CD25 [18]. The KIT mutant D816V is not detectable, but rarely other KIT mutations are found. MC are not spindle-shaped and never form compact focal infiltrates thus clearly contrasting to the common findings in SM. Immunohistochemical markers that should be applied in suspected MML are CD34, CD117, tryptase, and CD25.

\section{SM-AHNMD}

The association of SM with a non-mast cell hematological neoplasm is termed SM-AHNMD. Following ISM, SM-AHNMD represents the second most frequent subvariant of SM [19]. Almost all defined subtypes of myeloid neoplasms but also plasma cell myeloma and, very rarely, malignant lymphomas have been identified as 'AHNMD' [20]. SM-AHNMD is often a very challenging diagnosis for the hematopathologist and the various differential diagnoses depend on the degree of bone marrow infiltration.

(1) So-called occult SM is the most important differential diagnosis in cases with prominent 'AHNMD' which may completely obscure minor mast cell infiltrates. Infiltrates of SM may become visible in patients with SMAML only after cytoreductive therapy and remission of the 'AHNMD' [21]. Thus, patients show remission of an aggressive hematological neoplasm but now exhibit features of another less aggressive, clonal hematological tumor. Routine use of antibodies against tryptase, CD117 and CD25 enables to reveal associated ('occult') SM in not less than $5 \%$ of the cases. Such cases show a mild increase in loosely scattered often spindle-shaped mast cells with aberrant immunophenotype and CD25 expression but small compact infiltrates are hardly detected even after meticulous search.

(2) Regarding a minority of SM-AHNMD cases with diffuse-compact infiltration of the bone marrow, the initial diagnosis is aggressive SM or MCL. SM-AHNMD in such cases cannot be excluded unless cytomorphological evaluation of blood and bone marrow smears is performed.

(3) Many SM patients with marked persistent increase in circulating eosinophils clinically present with chronic eosinophilic leukemia (CEL, NOS) or myeloproliferative neoplasms with eosinophilia (MPNEo). Most cases of MPNEo exhibit a significant increase of spindle-shaped mast cells with aberrant immunophenotype and expression of CD25 but do not form compact (diagnostic) infiltrates (fig. 21-24). Evaluation of bone marrow histology may reveal SM-AHNMD (SMCEL/MPNEo) or 'pure' SM with eosinophilia ('SMEO'). It is important to be aware that SM-MPNEo does exist and morphological criteria of SM with multifocal compact mast cell infiltrates are clearly fulfilled [22]. However, synchronous occurrence of a cytogenetic anomaly in the PDGR (alpha or beta) which is crucial for the diagnosis of MPNEo with an activating point mutation KITD816V has not been published so far. This clearly contrasts to molecular pathological findings in all other subtypes of SM, where KITD816V is detectable in more than $90 \%$ of the cases [23].

(4) Synchronous existence of KITD816V and another important activating point mutation found in myeloproliferative neoplasms like polycythemia vera and primary myelofibrosis, namely JAK2V617F, has been shown and is found in SM associated with primary myelofibrosis. It is therefore recommended to look for 

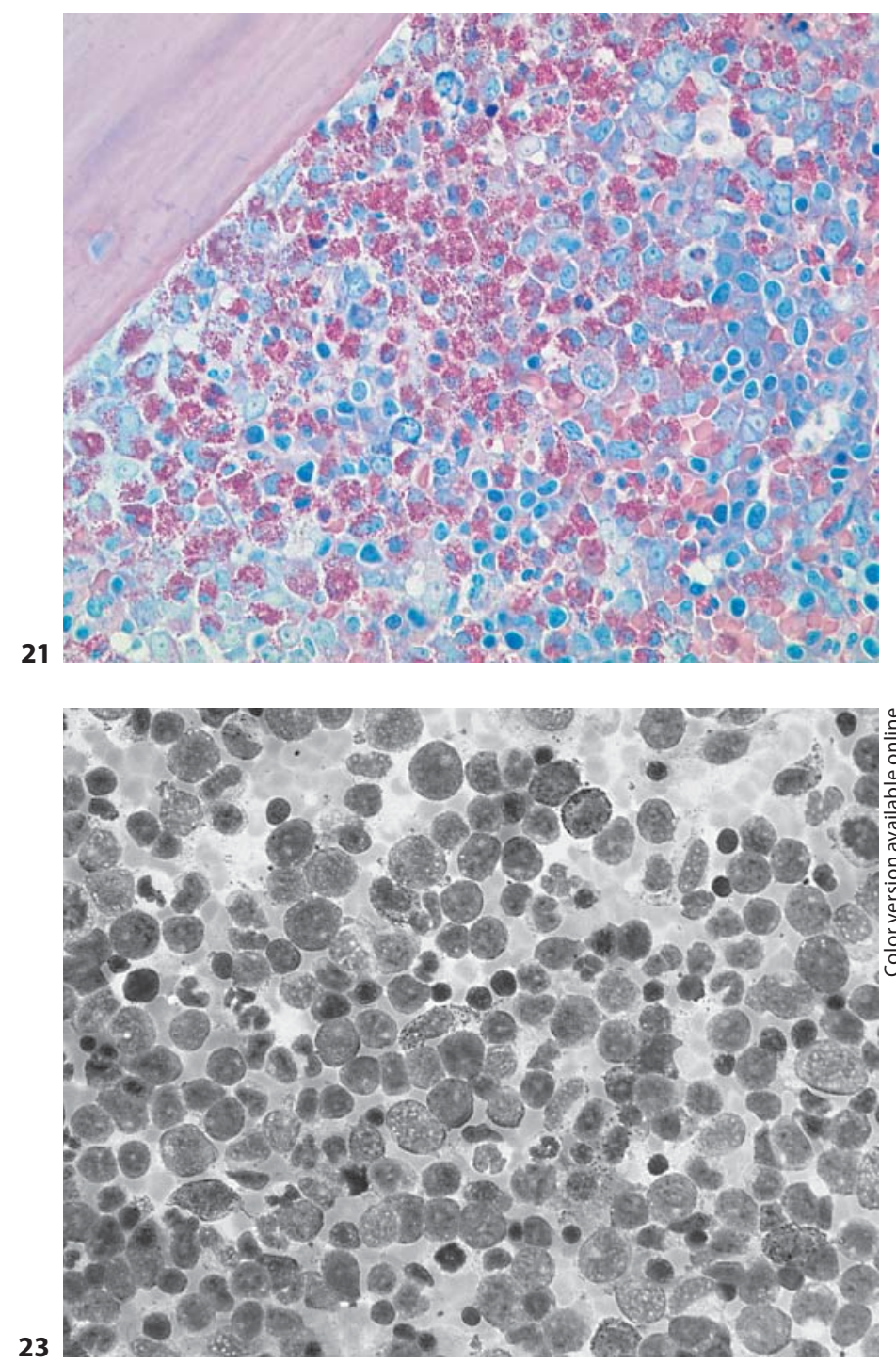

Fig. 21-24. Myeloproliferative neoplasm with eosinophilia (MPNEo). Bone marrow histology reveals dense infiltrates of eosinophilic granulocytes leading to the differential diagnoses of chronic eosinophilic leukemia (NOS) or myeloproliferative neoplasm with eosinophilia (MPNEo). Presence of large numbers of spindle-shaped mast cells with aberrant expression of CD25 is only seen in MPNEo. Since compact mast cell infiltrates are missed, di-

JAK2V617F in cases of SM-AHNMD with marked infiltration of the bone marrow and suspicion but not proof of an 'AHNMD' of myeloproliferative neoplasm type. However, it must also be considered that microdissected mast cells in cases of SM and associated primary myelofibrosis have been found to carry both activating mutations KITD816V and JAK2V617F [24].
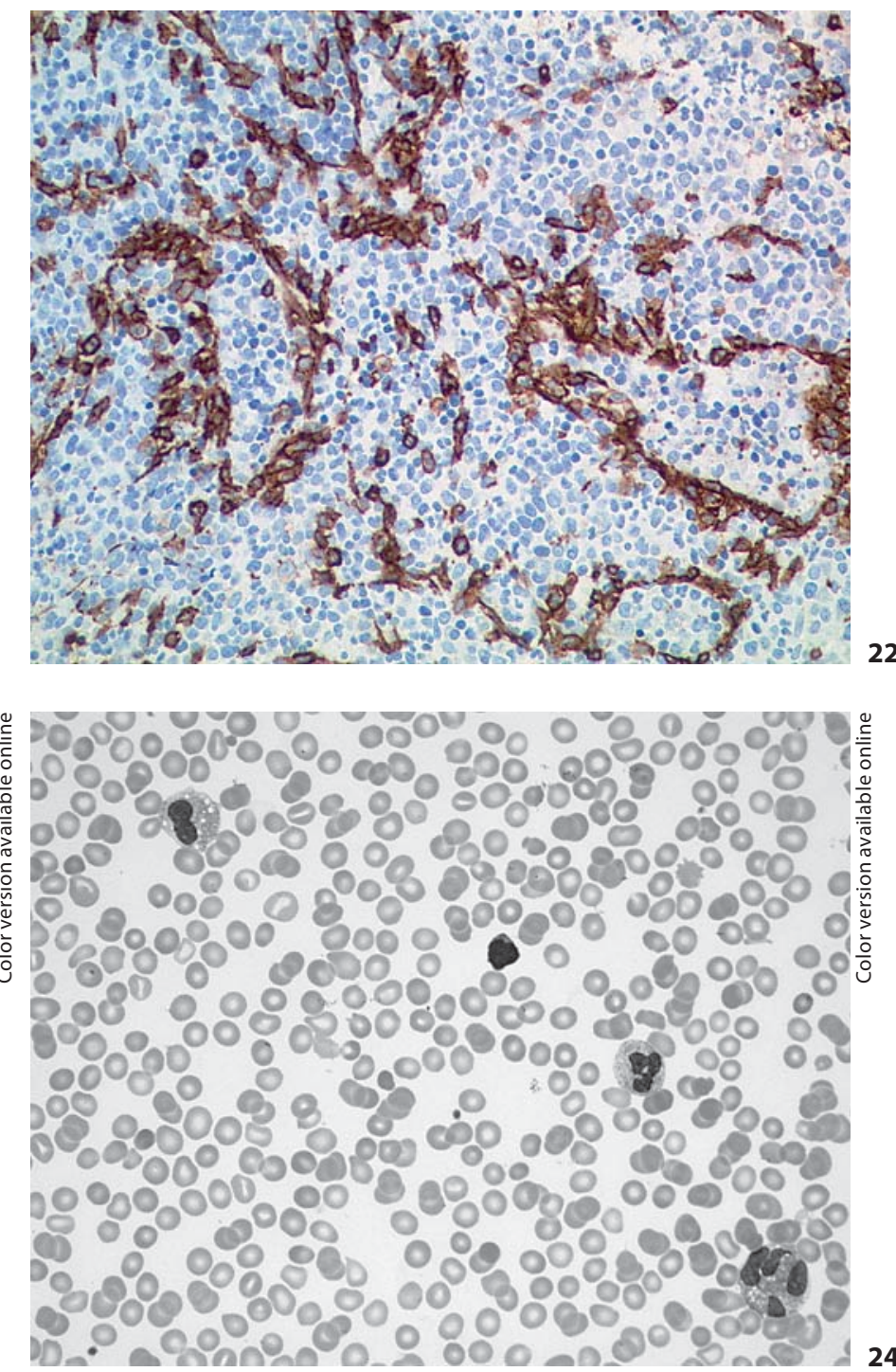

agnosis of SM-AHNMD cannot be established. Cytogenetic analysis showed presence of an anomaly in the PDGFR-alpha confirming diagnosis of MPNEo. Bone marrow smears also show abundant atypical hypogranulated loosely scattered mast cells and an increase in eosinophils. Blood smear contains atypical hypogranulated circulating eosinophils with hypersegmented nuclei. Giemsa (fig. 21). Anti-CD25 (ABC method) (fig. 22). Wright-Giemsa (fig. 23, 24).

\section{Take-Home Messages}

(1) Most cases of mastocytosis can be diagnosed and subtyped by the pathologist who should strictly apply defined WHO criteria.

(2) Compact tissue mast cell infiltrates are the morphological key finding to establish or exclude mastocytosis in the majority of cases. 
(3) Histological evaluation of a bone marrow trephine biopsy specimen is crucial for diagnosis of systemic mastocytosis.

(4) In a minority of cases diagnosis of mastocy tosis is only possible when molecular (KITD816V) and serological (elevated tryptase) parameters are also included in the diagnostic approach.
(5) Mastocytosis includes a great variety of differential diagnoses including basophilic, eosinophilic and monocytic leukemias but also overlap-syndromes like myelomastocytic leukemia.

(6) Differential diagnoses of mastocytoses differ greatly depending not only on the subtype of the disease and the degree of bone marrow infiltration but also on cytomorphological and immunophenotypical features of mast cells involved.

\section{References}

1 Valent P, Horny H-P, Escribano L, et al: Diagnostic criteria and classification of mastocytosis: a consensus proposal. Conference Report of 'Year 2000 Working Conference on Mastocytosis'. Leuk Res 2001;25:603-625.

$\checkmark 2$ Horny HP, Valent P: Diagnosis of mastocytosis: general histopathological aspects, morphological criteria, and immunohistochemical findings. Leuk Res 2001;25:543551.

3 Horny HP, Metcalfe DD, Bennett J, Bain BJ, Akin C, Escribano L, Valent P: Mastocytosis: World Health Organization (WHO) Classification of Tumours. Pathology and Genetics; in Jaffe ES, Harris NL, Stein H, Vardiman JW (eds): Tumours of Haematopoietic and Lymphoid Tissues. Geneva, WHO, 2008, vol 1.

4 Horny HP, Valent P: Histopathological and immunophenotypical aspects of mastocytosis. Int Arch Allergy Immunol 2002;127:115117.

5 Horny HP, Sotlar K, Stellmacher F, Krokowski M, Agis H, Schwartz LB, Valent P: The tryptase positive compact round cell infiltrate of the bone marrow (TROCI-bm): a novel histopathological finding requiring the application of lineage specific markers. J Clin Pathol 2006;59:298-302.

-6 Sotlar K, Horny HP, Simonitsch I, Krokowski M, Aichberger KJ, Mayerhofer M, Printz D, Fritsch G, Valent P: CD25 indicates the neoplastic phenotype of mast cells: a novel immunohistochemical marker for the diagnosis of systemic mastocytosis (SM) in routinely processed bone marrow biopsy specimens. Am J Surg Pathol 2004;28:1319-1325.

7 Maric I, Robyn J, Metcalfe DD, Fay MP, Carter M, Wilson T, Fu W, Stoddard J, Scott L, Hartsell M, Kirshenbaum A, Akin C, Nutman TB, Noel P, Klion AD: KITD816V-associated systemic mastocytosis with eosinophilia and FIP1L1/PDGFRA-associated chronic eosinophilic leukemia are distinct entities. J Allergy Clin Immunol 2007;120: 680-687.
8 Akin C, Fumo G, Yavuz AS, Lipsky PE, Neckers L, Metcalfe DD: A novel form of mastocytosis with a transmembrane c-kit mutation and response to imatinib. Blood 2004;103:3222-3225.

9 Horny H-P, Sillaber C, Menke D, Kaiserling E, Wehrmann M, Stehberger B, et al: Diagnostic utility of staining for tryptase in patients with mastocytosis. Am J Surg Pathol, 1998;22:1132-1140.

10 Sotlar K, Saeger W, Stellmacher F, Stahmer J, Jäckle S, Valent P, Horny H-P: 'Occult' mastocytosis with activating c-kit point mutation evolving into systemic mastocytosis associated with plasma cell myeloma and secondary amyloidosis. J Clin Pathol 2006; 59:875-878.

11 Caplan RM: The natural course of urticaria pigmentosa. Arch Dermatol 1963;87:146157.

12 Horny HP, Sotlar K, Stellmacher F, Valent P, Grabbe J: An unusual case of systemic mastocytosis associated with chronic lymphocytic leukaemia (SM-CLL). J Clin Pathol 2006;59:264-268.

13 Valent P, Akin C, Sperr WR, Escribano L, Arock M, Horny HP, Bennett JM, Metcalfe DD: Aggressive systemic mastocytosis and related mast cell disorders: current treament options and proposed response criteria. Leuk Res 2003;27:635-641.

14 Travis WD, Li CY, Hogaland HC, Travis LB, Banks PM: Mast cell leukemia: Report of a case and review of the literature. Mayo Clin Proc 1986;61:957-966.

15 Sperr WR, Escribano L, Jordan JH, Schernthaner GH, Kundi M, Horny HP, Valent P: Morphologic properties of neoplastic mast cells: delineation of stages of maturation and implication for cytological grading of mastocytosis. Leuk Res 2001;25:529-536.

16 Valent P, Samorapoompichit P, Sperr WR, Horny HP, Lechner K: Myelomastocytic leukemia: myeloid neoplasm characterized by partial differentiation of mast cell-lineage cells. The Hematology Journal 2002;3:9094 .
17 Gauer A, Hagen V, Merz H: A new sarcomatoid variant of multiple myeloma in a 20 year-old male. Ann Hematol 2004;83:251252.

18 Valent P, Sperr WR, Samorapoompichit P, Geissler K, Lechner K, Horny HP, Bennett JM: Myelomastocytic overlap syndromes: Biology, criteria, and relationship to mastocytosis. Leuk Res 2001;25:595-602.

19 Horny HP, Sotlar K, Sperr WR, Valent P: Systemic mastocytosis with associated clonal haematological non-mast cell lineage diseases: a histopathological challenge. J Clin Pathol 2004;57:604-608.

20 Sperr WR, Horny HP, Lechner K, Valent P: Clinical and biologic diversity of leukemias occurring in patients with mastocytosis. Leuk Lymphoma 2000;37:473-486.

21 Bernd HW, Sotlar K, Lorenzen J, Osieka R, Fabry U, Valent P, Horny HP: Acute myeloid leukemia with $\mathrm{t}(8 ; 21)$ associated with 'occult' mastocytosis: report of an unusual case and review of the literature. J Clin Pathol 2004; 57:324-328.

22 Pardanani A, Ketterling RP, Brockman SR, Flynn HC, Paternoster SF, Shearer BM, et al: CHIC2 deletion, a surrogate for FIP1L1PDGFRA fusion, occurs in systemic mastocytosis associated with eosinophilia and predicts response to imatinib mesylate therapy. Blood 2003;102:3093-3096.

23 Sotlar K, Colak S, Bache A. Berezowska S, Krokowski M, Bültmann B, Valent P, Horny $\mathrm{H}-\mathrm{P}$ : Variable presence of KIT(D816V) in clonal haematological non-mast cell diseases associated with systemic mastocytosis (SMAHNM). J Pathol 2010;220:586-595.

24 Sotlar K, Bache A, Stellmacher F, Bültmann B, Valent P, Horny HP: Systemic mastocytosis associated with chronic idiopathic myelofibrosis: a distinct subtype of systemic mastocytosis associated with a clonal hematological non-mast cell lineage disorder carrying the activating point mutations KITD816V and JAK2V617F. J Mol Diagn 2008;10:58-66. 